\title{
Coronary Flow Reserve Is a Comprehensive Indicator of Cardiovascular Risk Factors in Subjects With Chest Pain and Normal Coronary Angiogram
}

\author{
Dong-Hyeon Lee, MD; Ho-Joong Youn, MD; Yun-Seok Choi, MD; Chul-Soo Park, MD; \\ Jeong-Hwan Park, MD; Hui-Kyung Jeon, MD; Jae-Hyung Kim, MD
}

\begin{abstract}
Background: The aim of the present study was to analyze the parameters related to baseline coronary flow velocity (CFV) and coronary flow reserve (CFR) using Doppler transthoracic echocardiography (TTE), and to assess their associations with components of the Framingham risk score (FRS), which estimates 10-year risk of coronary heart disease, in subjects with chest pain and a normal coronary angiogram.

Methods and Results: A total of 354 individuals (mean age: $55 \pm 11$ years, M:F ratio=186:168) with angina or angina-like chest pain and a normal coronary arteriogram were enrolled. CFR, using TTE and adenosine or dipyridamole, was measured within 2 weeks after coronary angiogram. The clinical, electrocardiographic, echocardiographic and laboratory parameters related to baseline CVF and CFR were analyzed, and CFR was compared with FRS. There was an inverse correlation between baseline CFV and CFR ( $r=-0.374, P<0.001)$. On multivariate analysis the fulfilling of left ventricular hypertrophy criteria on electrocardiography was an independent predictor of baseline CFV for the upper $75 \%$ quartile $(23.2 \geq \mathrm{cm} / \mathrm{s}$; odds ratio $(\mathrm{OR})=2.840,95 \%$ confidence interval $(\mathrm{Cl})=$ 1.155-6.983, $\mathrm{P}=0.023)$. On multivariate analysis hemoglobin $\mathrm{A}_{1 \mathrm{c}}$ level was independently related to a $C F R<2.0$ $(\mathrm{OR}=2.195,95 \% \mathrm{Cl}=0.920-1.005, \mathrm{P}=0.013)$. CFR had an inverse correlation with $\mathrm{FRS}(\mathrm{r}=-0.222, \mathrm{P}<0.001)$. On multiple regression analysis among the components of the FRS system (FRSS), independent factors related to a CFR $<2.0$ included age $(\mathrm{OR}=1.033,95 \% \mathrm{Cl}=1.000-1.067, \mathrm{P}=0.041)$, high-density lipoprotein-cholesterol level $(\mathrm{OR}=0.961,95 \% \mathrm{Cl}=0.933-0.991, \mathrm{P}=0.012)$ and smoking status $(\mathrm{OR}=2.461,95 \% \mathrm{Cl}=1.078-5.618, \mathrm{P}=0.033)$, respectively.
\end{abstract}

Conclusions: CFR can be a comprehensive indicator of cardiovascular risk factors, including parameters of the FRSS, in subjects with chest pain and a normal coronary angiogram. (Circ J 2010; 74: 1405-1414) Key Words: Chest pain; Coronary flow reserve; Echocardiography; Framingham scores; Normal coronary angio-
gram

$\mathbf{E}$ ven if coronary angiography were $100 \%$ sensitive in detecting large-vessel coronary artery disease, it would identify only anatomic disease of the large vessels while providing no physiological information regarding myocardial ischemia, which accounts for the fact that $20-25 \%$ of patients who undergo coronary angiography for chest pain have normal or near-normal coronary angiogram results even though they have signs and symptoms of myocardial ischemia. ${ }^{1}$

\section{Editorial p1296}

Often, chest pain in these patients has been ascribed to a non-cardiac etiology, ${ }^{2}$ and although the finding of normal coronary angiogram may be reassuring to the patient as well as to the physician, a significant number of these patients continue to experience typical or sometimes atypical chest pain that requires anti-anginal medications on a continual basis, with some requiring readmission to the hospital for severe chest pain. Therefore, a normal coronary angiogram itself may not provide any benefit to the patient or the physician. ${ }^{3}$

In the context of chest pain, the presence of ST-segment depression during rapid atrial pacing and normal coronary angiogram findings has been termed "microvascular angina", which has been classified as a form of angina pectoris; but despite much research and interest, the characterization of this disease remains elusive. ${ }^{4}$

Received November 18, 2009; revised manuscript received February 18, 2010; accepted March 7, 2010; released online May 18, 2010

Time for primary review: 21 days

Division of Cardiology, Department of Internal Medicine, College of Medicine, Catholic University of Korea, Seoul, Korea

Mailing address: Ho-Joong Youn, MD, PhD, Seoul St Mary's Hospital, Division of Cardiology, Department of Internal Medicine, College of Medicine, Catholic University of Korea, \#505 Banpo-dong, Seocho-gu, Seoul 137-701, Korea. E-mail: younhj@catholic.ac.kr

ISSN-1346-9843 doi:10.1253/circj.CJ-09-0897

All rights are reserved to the Japanese Circulation Society. For permissions, please e-mail: cj@j-circ.or.jp 
Table 1. Clinical Characteristics for CFR and Baseline CFV $n=354$

Demographics

Age (years)

Male (\%)

Menopause (\%)

HTN (\%)

NIDDM (\%)

Smoking (\%)

SBP $(\mathrm{mmHg})$

$\mathrm{DBP}(\mathrm{mmHg})$

HR (beats/min)

BMI $\left(\mathrm{kg} / \mathrm{cm}^{2}\right)>25$

LVH on ECG (\%)

Exercise treadmill test

Positive (\%)

Negative (\%)

Equivocal (\%)

Incomplete (\%)

Echocardiography

LVMI $\left(\mathrm{g} / \mathrm{m}^{2}\right)$

$\operatorname{LVEF}(\%)$

LVEDV (ml)

LVESV (ml)

FS (\%)

LVEDd $(\mathrm{mm})$

LVESd (mm)

IVS (mm)

PW $(\mathrm{mm})$

\section{Laboratory findings}

WBC (counts/L)

$\mathrm{Hb}(\mathrm{g} / \mathrm{dl})$

Platelet (counts $\times 10^{3} / \mathrm{L}$ )

FBS (mg/dl)

$\mathrm{Hb} A_{1 c}(\%)$

hs-CRP (mg/L)

$\mathrm{TC}(\mathrm{mg} / \mathrm{dl})$

$\mathrm{TG}(\mathrm{mg} / \mathrm{dl})$

HDL-C (mg/dl)

LDL-C (mg/dl)

${ }^{\star} \mathrm{P}<0.05$, relationship with CFR (Student's unpaired $t$-test); ${ }^{\mathrm{P}} \mathrm{P}<0.05$, relationship with CFR (chi-square test); $\mathrm{P}<0.05$, relationship with baseline CFV (chi-square test); $\$ \mathrm{P}<0.05$, relationship with baseline CFV (Student's unpaired t-test).

CFR, coronary flow reserve; CFV, coronary flow velocity; HTN, hypertension; NIDDM, non-insulin-dependent diabetes mellitus; SBP, systolic blood pressure; DBP, diastolic blood pressure; HR, heart rate; $\mathrm{BMI}$, body mass index; $\mathrm{LVH}$, left ventricular hypertrophy; ECG, electrocardiography; LVMI, left ventricular mass index; LVEF, left ventricular ejection fraction; LVEDV, left ventricular end diastolic volume; LVESV, left ventricular end systolic volume; FS, fractional shortening; LVEDd, left ventricular end diastolic dimension; LVESd, left ventricular end systolic dimension; IVS, interventricular septum; PW, posterior wall; WBC, white blood cell; Hb, hemoglobin; FBS, fasting blood glucose; hs-CRP, high-sensitivity C-reactive protein; TC, total cholesterol; TG, triglyceride; HDL-C, high-density lipoprotein-cholesterol; LDL-C, low-density lipoprotein-cholesterol.

Coronary flow reserve (CFR) has proven useful in the risk assessment of patients undergoing coronary angiographic assessment. Several invasive methods have been used to measure CFR including Doppler-tip catheter, Doppler-tip guidewire, digital subtraction angiogram, and coronary sinus ther- modilution..$^{5-7}$ The measurement of CFR using transthoracic echocardiography (TTE) has been used as a non-invasive method of measuring CFR since Hozumi et al reported that it was an accurate method that had a correlation coefficient of 0.94 with Doppler guidewire, ${ }^{8}$ which was considered as the standard method for measuring CFR. ${ }^{9-21}$ Although the normal and ischemic ranges of CFR have not been determined as yet, CFR $>3.0$ has been reported as normal while CFR $<2.0$ have been suggested to be in an ischemic range in patients with significant epicardial coronary artery stenosis. ${ }^{11,12}$

In terms of cardiovascular risk factor assessment in general, according to the Third Report of the National Cholesterol Education Program (NCEP) Expert Panel on Detection, Evaluation, and Treatment of High Blood Cholesterol in Adults (Adult Treatment Panel III), the risk assessment for determining the 10-year risk for developing coronary heart disease (CHD) in subjects without CHD is carried out using the Framingham risk scoring system with distinction of gender. The risk factors included in the Framingham calculation of 10-year risk are: age, total cholesterol, high-density lipoprotein-cholesterol (HDL-C), systolic blood pressure, treatment for hypertension, and cigarette smoking. ${ }^{22}$

Although Framingham risk scoring is a useful tool to assess risk of a first cardiovascular event in a community-based cohort without overt CHD, its prognostic value in individuals with chest pain and normal angiogram is unknown. The aim of the present study was to analyze the parameters related to baseline coronary flow velocity (CFV) and CFR using TTE and to assess their associations with components of the Framingham risk score (FRS), which estimates 10-year risk of $\mathrm{CHD}$, in subjects with chest pain and a normal coronary angiogram.

\section{Methods}

\section{Patients}

The present study included 354 patients (M:F=186:168, mean age $=55 \pm 11$ years) with normal coronary angiograms who presented with chest pain from January 2000 to June 2007 to St Mary's Hospital, Catholic University of Korea.

All patients underwent electrocardiography (ECG), exercise treadmill test and TTE, and those with a past history of myocardial infarction, atrial fibrillation or left bundle branch block on ECG, primary valvular heart disease, hypertrophic cardiomyopathy, regional wall motion abnormalities or ejection fraction $<50 \%$ on echocardiogram, positive spasm test with acetylcholine chloride (Zeria Pharmaceutical, Tokyo, Japan) and those with even minimal stenosis apparent on coronary angiography were excluded from the study.

This study was approved by the Institutional Review Committee of St Mary's Hospital, Catholic University of Korea. The participants were informed of the investigative nature of the study and written informed consent was obtained before enrollment (SC8RASI0141).

\section{ECG}

The diagnosis of left ventricular hypertrophy $(\mathrm{LVH})$ criteria on ECG has been defined by the Sokolow-Lyon index as a sum of SV1+RV5 or $\mathrm{V}_{6}>3.5 \mathrm{mV} .{ }^{23} \mathrm{LVH}$ criteria on ECG were analyzed by 2 experienced electrocardiographers.

\section{Exercise Treadmill Test (ETT)}

The ETT was conducted using the Quinton 5000 model, and the results were interpreted based on the American College of Cardiology/American Heart Association (ACC/AHA) guide- 
A

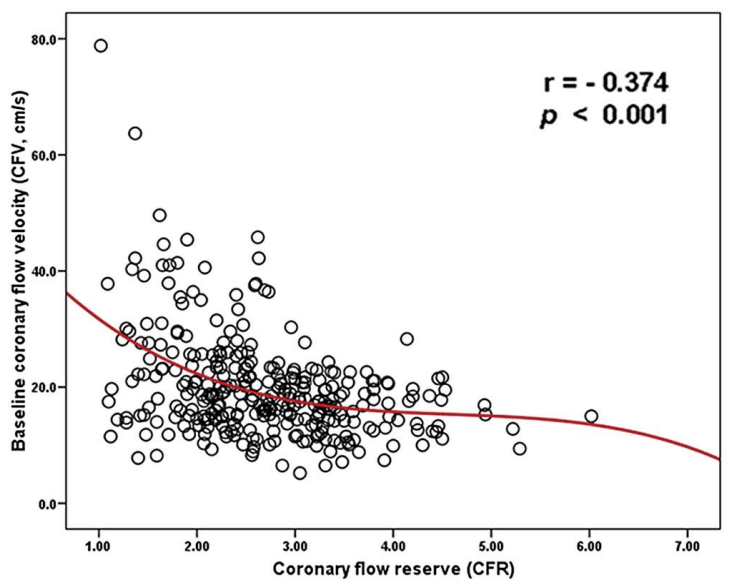

B

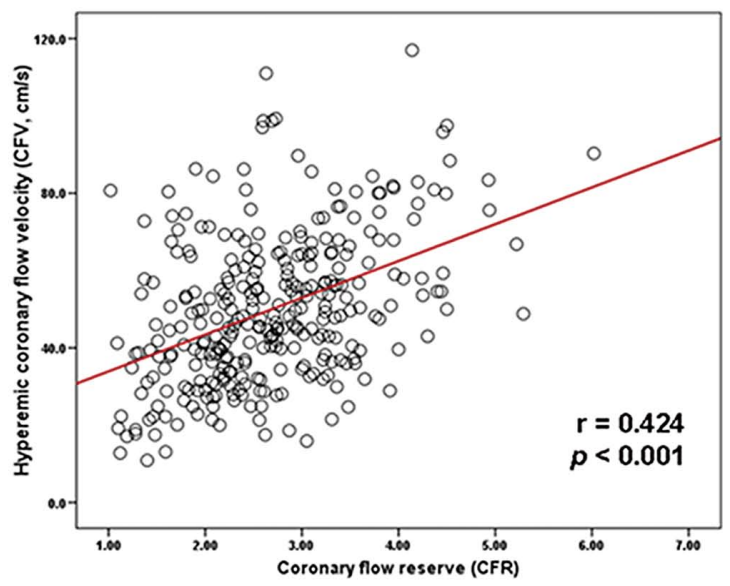

Figure 1. Relationship between (A) baseline and (B) hyperemic coronary flow velocity and coronary flow reserve.

lines, being thereby scored as negative, positive, incomplete, or equivocal. ${ }^{24}$ Positive results reflected typical symptoms during the ETT regardless of reaching the target heart beat, with significant ST-segment depression (based on baseline, ST segments had $>0.1-\mathrm{mV}$ horizontal or downslope depression that was maintained for $>0.08 \mathrm{~s}$ ).

\section{Echocardiography}

TTE was performed using a Sonos 5500 echocardiograph (Phillips, Andover, MA, USA) and a multifrequency transducer. Measurements of left ventricular end-diastolic volume, left ventricular end-systolic volume, and left ventricular ejection fraction were done by manual tracing of an endocardial border from apical 4- and 2-chamber views, as recommended by the American Society of Echocardiography. ${ }^{25}$

\section{Framingham Risk Scoring System}

The FRS was calculated on the basis of a number of categorical variables, including age, total cholesterol, HDL-C, systolic blood pressure, treatment for hypertension, and cigarette smoking. ${ }^{22}$ The 10 -year risk for myocardial infarction and coronary death (hard CHD) is estimated from total points, and the person is categorized according to absolute 10 -year risk as indicated in the previous section. ${ }^{22}$

\section{CFV and CFR in the Distal Left Anterior Descending (LAD) Coronary Artery on TTE}

TTE for CFV was performed within $24-48 \mathrm{~h}$ of coronary angiography. After placing the 12-MHz high-frequency transducer (Ultraband, H-P Sonos 5500, USA) between the 4th and 5th intercostal space with the patient positioned in the left lateral decubitus position, we modified the apical 2-chamber view to visualize the distal LAD coronary artery and used color Doppler in the low velocity range (Nyquist limit set at $10-20 \mathrm{~cm} / \mathrm{s}$ ) to optimize color flow imaging. For optimizing flow sample during diastole, we adjusted the probe angle to orient the Doppler ultrasound beam parallel to the coronary flow. If the angle between the Doppler ultrasound beam and coronary flow exceeded $30^{\circ}$, angle correction was performed using the standard software package of the ultrasound system. The spectral Doppler signals of the distal LAD displayed the characteristic biphasic flow pattern, with a diastolic dominant flow and a smaller systolic component. Peak systolic velocity and peak diastolic velocity were measured at baseline and under hyperemic conditions that were obtained with iv infusion of adenosine $\left(140 \mu \mathrm{g} \cdot \mathrm{kg}^{-1} \cdot \mathrm{min}^{-1}\right.$, Sanofi-Aventis, Paris, France) or dipyridamole $(0.56 \mathrm{mg} / \mathrm{kg}$, Boehringer Ingelheim, Ingelheim, Germany) over $4 \mathrm{~min}$. An average peak diastolic velocity was calculated from more than 3 cardiac cycles, and blood pressure and heart rate were also measured for the same cycles. CFR was calculated as the ratio of hyperemic to baseline peak diastolic velocity.

All patients had continuous transcutaneous oximetric and ECG monitoring as well as frequent blood pressure monitoring before, during and after TTE. Throughout the procedure the patient was questioned by the operator for the presence of chest pain. TTE for CFV was performed by one experienced operator, and CFV measurements were analyzed by 2 experienced investigators in a blinded fashion. All studies were continuously recorded on $1 / 2$-in super-VHS videotape for off-line analysis. On TTE, CFV in the distal LAD coronary artery $<14 \mathrm{~cm} / \mathrm{s}$ was defined as slow flow. ${ }^{10}$ CFR $<2.0$ has been defined as an ischemic range of CFR in patients. ${ }^{11,12}$

\section{Coronary Angiography}

Coronary angiography was performed in all patients from the femoral approach with standard catheters from conventional views. Nitroglycerin was not given before angiography. For the provocation test of coronary artery spasm, acetylcholine was injected in incremental doses of 20,50 , and $80 \mu \mathrm{g}$ into the RCA and of 20,50, and $100 \mu \mathrm{g}$ into the left coronary artery. ECG and coronary angiography were repeated to confirm the presence of spasms. The angiograms were analyzed by 2 experienced angiographers.

\section{Statistical Analysis}

All data are expressed as mean $\pm \mathrm{SD}$, and statistical analyses were performed using the SAS statistical software version 9.1 (SAS Institute, Cary, NC, USA). Unpaired t-test was used to analyze differences in continuous variables, and analysis of categorical data was performed using the chi-squared test. 
A

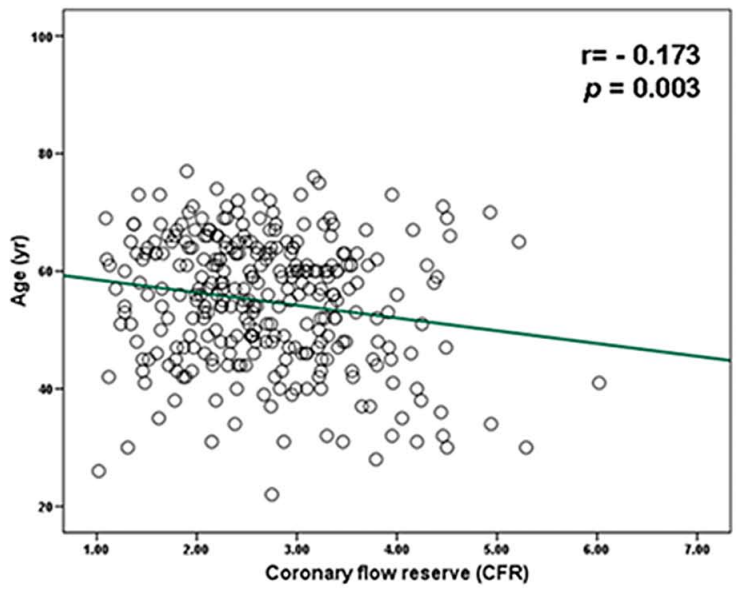

C

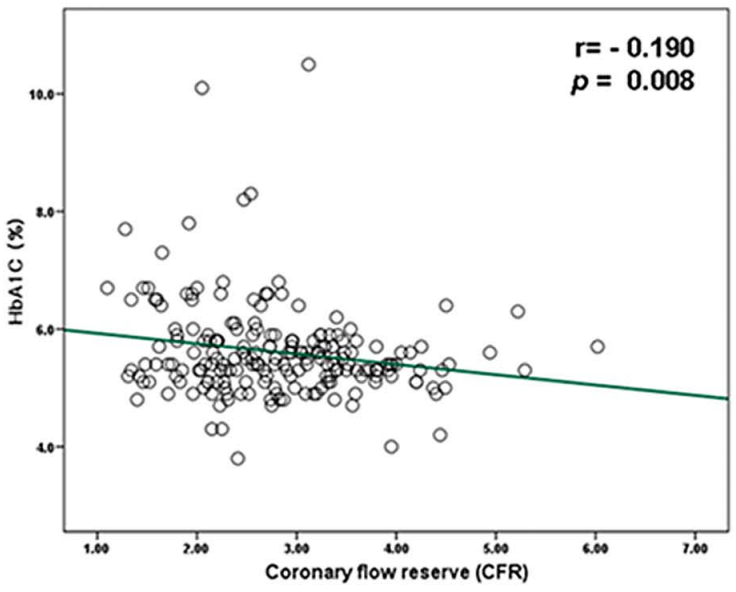

B

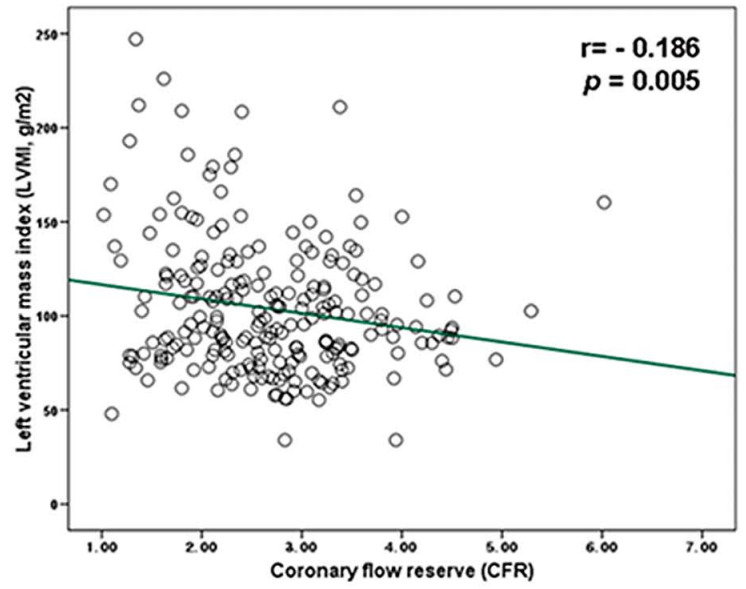

D

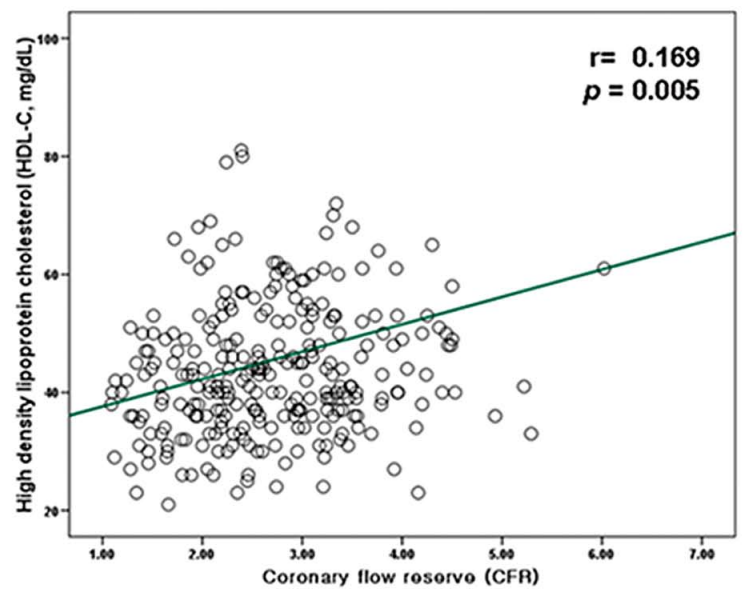

E

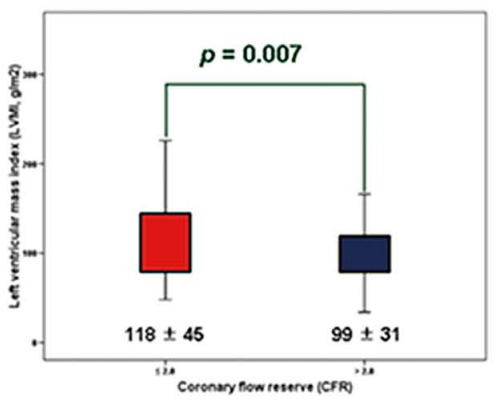

F

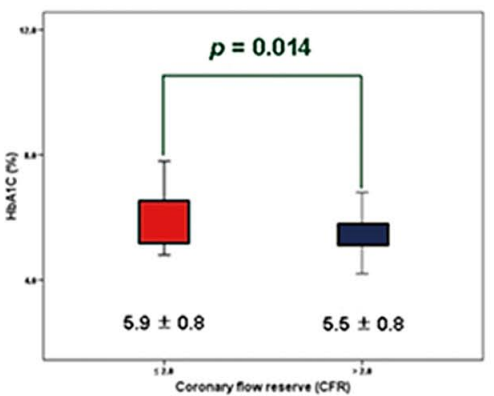

G

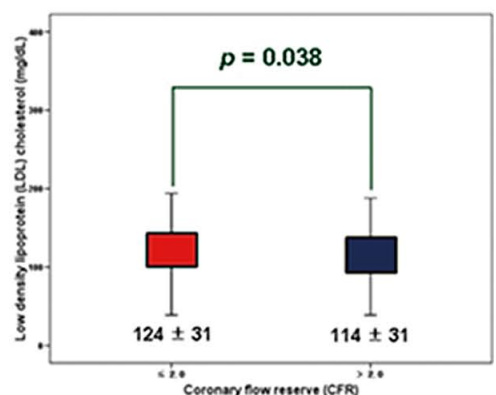

Figure 2. Parameters associated with coronary flow reserve (CFR): (A) age, (B) left ventricular mass index (LVMI), (C) hemoglobin $A_{1 c}\left(H_{b A_{1 c}}\right)$ and $(D)$ high-density lipoprotein-cholesterol. Comparison with the 2 groups divided by a CFR of 2.0: (E) LVMI, (F) $\mathrm{HbA}_{1 \mathrm{c}}$ and (G) low-density lipoprotein-cholesterol.

The relationships between parameters related to baseline CFV or CFR and FRS were assessed using Spearman's correlation coefficient by rank. To identify independent risk factors that could predict 10-year coronary death on FRS, we used multiple logistic regression analysis and calculated odds ratios (OR) and $95 \%$ confidence intervals $(95 \% \mathrm{CI})$; the following parameters were used: age, total cholesterol level, HDL-C level, systolic blood pressure, treatment for hypertension, and cigarette smoking. Analysis for the 3 categorical groups, namely the $\mathrm{CFR}<2.0,2 \leq \mathrm{CFR}<3$ and $\mathrm{CFR} \geq 3$ groups, was performed using the chi-square test. Statistical significance was defined as $\mathrm{P}<0.05$. 


\begin{tabular}{|c|c|c|c|}
\hline $\mathrm{n}=354$ & CFR $<2.0(n=78)$ & CFR $\geq 2.0(n=276)$ & $P$ value \\
\hline \multicolumn{4}{|l|}{ Demographics } \\
\hline Age (years) & $56 \pm 11$ & $55 \pm 11$ & 0.350 \\
\hline Male (\%) & $42(53.8)$ & $144(52.2)$ & 0.890 \\
\hline Postmenopause (\%) & $40(51.3)$ & $128(46.4)$ & 0.392 \\
\hline HTN (\%) & $40(51.3)$ & $130(47.1)$ & 0.679 \\
\hline NIDDM (\%) & $13(16.7)$ & $33(12.0)$ & 0.310 \\
\hline Smoking (\%) & 27 (34.6) & $64(23.2)$ & 0.044 \\
\hline $\mathrm{SBP}(\mathrm{mmHg})$ & $122 \pm 21$ & $120 \pm 20$ & 0.615 \\
\hline $\mathrm{DBP}(\mathrm{mmHg})$ & $70 \pm 12$ & $69 \pm 13$ & 0.522 \\
\hline HR (beats/min) & $64 \pm 9$ & $66 \pm 11$ & 0.233 \\
\hline BMI $\left(\mathrm{kg} / \mathrm{cm}^{2}\right)>25$ & $25.1 \pm 2.7$ & $25.1 \pm 2.9$ & 0.237 \\
\hline LVH on ECG (\%) & $41(52.6)$ & $64(23.2)$ & 0.014 \\
\hline Exercise time (min) & $7.8 \pm 3.0$ & $8.4 \pm 2.8$ & 0.112 \\
\hline METs & $9.2 \pm 2.4$ & $9.7 \pm 2.8$ & 0.107 \\
\hline Double product (mmHg×beats/min) & $25,829 \pm 6,141$ & $26,215 \pm 6,323$ & 0.652 \\
\hline \multicolumn{4}{|l|}{ Echocardiography } \\
\hline LVMI $\left(\mathrm{g} / \mathrm{m}^{2}\right)$ & $118 \pm 45$ & $99 \pm 31$ & 0.007 \\
\hline LVEF (\%) & $62.9 \pm 11.1$ & $65.0 \pm 9.0$ & 0.169 \\
\hline LVEDV (ml) & $65 \pm 27$ & $68 \pm 23$ & 0.405 \\
\hline LVESV (ml) & $24 \pm 14$ & $24 \pm 10$ & 0.773 \\
\hline FS (\%) & $41.0 \pm 11.6$ & $39.3 \pm 9.4$ & 0.366 \\
\hline LVEDd (mm) & $48 \pm 8$ & $48 \pm 7$ & 0.913 \\
\hline LVESd (mm) & $30 \pm 10$ & $30 \pm 7$ & 0.781 \\
\hline IVS (mm) & $13 \pm 8$ & $10 \pm 3$ & 0.009 \\
\hline $\mathrm{PW}(\mathrm{mm})$ & $13 \pm 7$ & $10 \pm 4$ & 0.038 \\
\hline \multicolumn{4}{|l|}{ Laboratory findings } \\
\hline WBC (counts/L) & $6,926 \pm 2,189$ & $6,683 \pm 3,357$ & 0.595 \\
\hline $\mathrm{Hb}(\mathrm{g} / \mathrm{dl})$ & $13.7 \pm 1.7$ & $13.3 \pm 1.5$ & 0.073 \\
\hline Platelet (counts $\times 10^{3} / \mathrm{L}$ ) & $226 \pm 54$ & $244 \pm 67$ & 0.082 \\
\hline FBS (mg/dl) & $116 \pm 27$ & $111 \pm 28$ & 0.197 \\
\hline $\mathrm{HbA}_{1 \mathrm{c}}(\%)$ & $5.9 \pm 0.8$ & $5.5 \pm 0.8$ & 0.014 \\
\hline hs-CRP (mg/L) & $2.61 \pm 4.54$ & $2.15 \pm 3.86$ & 0.482 \\
\hline $\mathrm{TC}(\mathrm{mg} / \mathrm{dl})$ & $191 \pm 35$ & $186 \pm 35$ & 0.365 \\
\hline $\mathrm{TG}(\mathrm{mg} / \mathrm{dl})$ & $159 \pm 93$ & $143 \pm 84$ & 0.197 \\
\hline HDL-C (mg/dl) & $40 \pm 10$ & $47 \pm 27$ & 0.063 \\
\hline LDL-C (mg/dl) & $124 \pm 31$ & $114 \pm 31$ & 0.038 \\
\hline
\end{tabular}

METs, metabolic equivalents. Other abbreviations see in Table 1.

\section{Results}

\section{Clinical Characteristics}

The mean age of the 354 patients studied was $55 \pm 11$ years; there were more male $(n=186)$ than female $(n=168)$ participants. A total of 143 of 168 (40.4\%) female patients were postmenopausal. The prevalence of hypertension, diabetes mellitus, and current smoker status was $48.0 \%, 13.0 \%$ and $25.7 \%$, respectively. The categorical finding of TMT according to Bruce's protocol was positive $51.7 \%$, negative $16.4 \%$, equivocal $11.6 \%$ and incomplete $20.3 \%$, respectively (Table 1). Clinical, demographic, echocardiogaphic and laboratory findings, and the relationships between relevant variables and CFR/baseline CFV are presented in Table 1.

\section{Parameters Associated With CFR and Baseline CFV}

CFR and Baseline CFV A statistically significant inverse correlation was present between CFR $(2.69 \pm 0.87)$ and baseline CFV (20.0 $\pm 9.4 \mathrm{~cm} / \mathrm{s} ; \mathrm{r}=-0.374, \mathrm{P}<0.001$; Figure $1 \mathrm{~A})$. In con- trast, there was a positive correlation between CFR and hyperemic CFV (50.0 $\pm 19.4 \mathrm{~cm} / \mathrm{s}, \mathrm{r}=0.424, \mathrm{P}<0.001$; Figure 1B).

Parameters Associated With CFR CFR was positively correlated with HDL-C level ( $\mathrm{r}=0.169, \mathrm{P}=0.005$; Figure 2D) and it was negatively correlated with age $(\mathrm{r}=-0.173, \mathrm{P}=0.003$; Figure 2A), left ventricular mass index (LVMI; $r=-0.186$, $\mathrm{P}=0.005$; Figure 2B) on echocardiography, and hemoglobin $\mathrm{A}_{1 \mathrm{c}}\left(\mathrm{HbA}_{1 \mathrm{c}} ; \mathrm{r}=-0.190, \mathrm{P}=0.008\right.$, Figure 2C).

In the 2 groups divided by a CFR of 2.0, LVMI (118 $45 \mathrm{~g} / \mathrm{m}^{2}$ vs $99 \pm 31 \mathrm{~g} / \mathrm{m}^{2}, \mathrm{P}=0.007$; Figure $2 \mathrm{E}$ ) on echocardiography, $\mathrm{HbA}_{1 \mathrm{c}}(5.9 \pm 0.8 \%$ vs $5.5 \pm 0.8 \%, \mathrm{P}=0.014$; Figure $2 \mathrm{~F}$ ) and low-density lipoprotein-cholesterol (LDL-C) level (124士 $31 \mathrm{mg} / \mathrm{dl}$ vs $114 \pm 31 \mathrm{mg} / \mathrm{dl}, \mathrm{P}=0.038$, respectively; Figure $2 \mathrm{G}$ ) were significantly higher in the CFR $<2.0$ group than in the CFR $\geq 2.0$ group, respectively (Table 2 ). But there were no significant differences between the 2 groups in exercise time (7.8 $\pm 3.0 \mathrm{~min}$ vs $8.4 \pm 2.8 \mathrm{~min}, \mathrm{P}=0.112$, respectively), metabolic equivalent $(9.2 \pm 2.4$ vs $9.7 \pm 2.8, \mathrm{P}=0.107$, respectively) and double product $(25,829 \pm 6,141 \mathrm{mmHg} \times$ beats/min vs $26,215 \pm$ 


\begin{tabular}{|c|c|c|c|}
\hline & OR & $95 \% \mathrm{Cl}$ & $P$ value \\
\hline \multicolumn{4}{|c|}{ Independent factors related to CFR $<2.0$} \\
\hline Age & 1.017 & $0.974-1.062$ & 0.446 \\
\hline LVH on ECG & 1.995 & $0.761-5.228$ & 0.160 \\
\hline LVMI on echocardiography & 1.007 & $0.994-1.020$ & 0.286 \\
\hline $\mathrm{HbA}_{1 \mathrm{c}}$ & 2.195 & $0.920-1.005$ & 0.013 \\
\hline HDL-C & 0.961 & $0.995-1.088$ & 0.080 \\
\hline \multicolumn{4}{|c|}{$\begin{array}{l}\text { Independent factors related to baseline CFV for } \\
\text { the highest } 75 \% \text { quartile }(\geq 23.2 \mathrm{~cm} / \mathrm{s})\end{array}$} \\
\hline Age & 1.018 & $0.974-1.064$ & 0.424 \\
\hline HTN & 1.005 & $0.416-2.431$ & 0.991 \\
\hline Diabetes mellitus & 1.272 & $0.341-4.752$ & 0.720 \\
\hline SBP & 1.007 & $0.977-1.039$ & 0.640 \\
\hline DBP & 1.021 & $0.976-1.069$ & 0.361 \\
\hline LVH on ECG & 2.840 & $1.155-6.983$ & 0.023 \\
\hline LVMI on echocardiography & 1.000 & $0.988-1.012$ & 0.984 \\
\hline $\mathrm{HbA}_{1 c}$ & 1.159 & $0.566-2.369$ & 0.687 \\
\hline HDL-C & 1.005 & $0.993-1.017$ & 0.441 \\
\hline \multicolumn{4}{|c|}{$\begin{array}{l}\text { Independent factors related to CFR }<2.0 \text { among } \\
\text { the components of the Framingham risk scoring system }\end{array}$} \\
\hline Gender (male) & 1.517 & $0.690-3.337$ & 0.300 \\
\hline Age & 1.033 & $1.000-1.067$ & 0.041 \\
\hline TC level & 1.004 & $0.995-1.013$ & 0.340 \\
\hline HDL-C level & 0.961 & $0.933-0.991$ & 0.012 \\
\hline SBP & 0.998 & $0.983-1.013$ & 0.763 \\
\hline Smoking status & 2.461 & $1.078-5.618$ & 0.033 \\
\hline \multicolumn{4}{|c|}{ Independent factors related to $\mathrm{CFR}<2.0$ via telephone interview } \\
\hline HDL-C & 0.934 & $0.891-0.980$ & 0.005 \\
\hline $\mathrm{Hb}$ & 0.394 & $0.138-1.128$ & 0.083 \\
\hline Hematocrit & 1.531 & $1.036-2.264$ & 0.033 \\
\hline
\end{tabular}

OR, odds ratio; $\mathrm{Cl}$, confidence interval. Other abbreviations see in Table 1.

$6,323 \mathrm{mmHg} \times$ beats $/ \mathrm{min}, \mathrm{P}=0.652$, respectively) according to Bruce's protocol (Table 2).

On multivariate analysis the independent factor related to CFR $<2.0$ defined as an ischemic range of CFR, was $\mathrm{HbA}_{1 c}$ level $(\mathrm{OR}=2.195,95 \% \mathrm{CI}=0.920-1.005, \mathrm{P}=0.013$; Table 3$)$.

Parameters Associated With Baseline CFV Baseline CFV was positively correlated with systolic blood pressure $(\mathrm{r}=0.175, \mathrm{P}=0.002$; Figure 3A), diastolic blood pressure $(\mathrm{r}=0.132, \mathrm{P}=0.018$; Figure 3B), LVMI $(\mathrm{r}=0.237, \mathrm{P}<0.001$; Figure $3 \mathrm{C})$ on echocardiography, and $\mathrm{HbA}_{1 \mathrm{c}}(\mathrm{r}=0.186, \mathrm{P}=$ 0.006; Figure 3D).

The baseline CFV in the hypertensive group was significantly higher than in the normotensive group $(21.7 \pm 9.5 \mathrm{~cm} / \mathrm{s}$ vs $18.4 \pm 9.0 \mathrm{~cm} / \mathrm{s}, \mathrm{P}=0.002$; Figure $3 \mathrm{E}$ ); $\mathrm{CVF}$ in the diabetes mellitus group was higher than in the non-diabetes mellitus group $(23.0 \pm 12.7 \mathrm{~cm} / \mathrm{s}$ vs $19.5 \pm 8.6 \mathrm{~cm} / \mathrm{s}, \mathrm{P}=0.024$; Figure $3 \mathrm{~F})$, and CVF in the LVH group was higher than in the non-LVH group $(23.7 \pm 12.6 \mathrm{~cm} / \mathrm{s}$ vs $18.0 \pm 6.8 \mathrm{~cm} / \mathrm{s}, \mathrm{P}<0.001$; Figure $3 \mathrm{G})$.

LVH criteria on ECG were an independent predictor of the baseline $\mathrm{CFV}$ on highest $75 \%$ quartile $(23.2 \mathrm{zm} / \mathrm{s}$; OR= 2.840, 95\% CI =1.155-6.983, $\mathrm{P}<0.023$; Table 3 ).

\section{CFR and Framingham Risk Scoring System}

The CFR had an inverse correlation with the FRS-estimated 10 -year risk for $\mathrm{CHD}(\mathrm{r}=-0.222, \mathrm{P}<0.001$; Figure 4A).

We divided study participants into 3 categorical groups, namely $\mathrm{CFR}<2.0$ as an ischemic range, $2 \leq \mathrm{CFR}<3$ and $\mathrm{CFR}$ $\geq 3$ as a normal range. FRS was $12.6 \pm 4.4$ in the $C F R<2.0$ group, $10.9 \pm 5.5$ in the $2 \leq \mathrm{CFR}<3$ group, and $9.75 \pm 5.9$ in the CFR $\geq 3.0$ group, respectively. FRS was significantly higher in the $C F R<2.0$ group relative to the $C F R \geq 3.0$ group $(\mathrm{P}<$ 0.001 ; Figure 4B).

Among components of the Framingham risk scoring system, including age, total cholesterol level, HDL-C level, systolic blood pressure, treatment for hypertension, and cigarette smoking, independent factors related to $\mathrm{CFR}<2.0$ on multiple regression analysis were age $(\mathrm{OR}=1.033,95 \% \mathrm{CI}=1.000$ $1.067, \mathrm{P}=0.041)$, HDL-C level $(\mathrm{OR}=0.961,95 \% \mathrm{CI}=0.933-$ $0.991, \mathrm{P}=0.012)$ and smoking status $(\mathrm{OR}=2.461,95 \% \mathrm{CI}=$ 1.078-5.618, $\mathrm{P}=0.033$ ), respectively (Table 3 ).

Long-Term Outcome Data Collected via Telephone Interview During a mean follow up of 45 \pm 21 months (range, 12-109 months), 2 patients died due to non-cardiac cause. A total of $137(71 \%)$ among 193 patients who responded to the telephone interview were being treated. Of these, the CFR was significantly related to the HDL-C level $(r=0.267, \mathrm{P}=0.001)$, hemoglobin level $(\mathrm{r}=-0.195, \mathrm{P}=0.004)$ and hematocrit level $(\mathrm{r}=-0.195, \mathrm{P}=0.040)$, respectively. On multivariate analysis the independent factors related to $\mathrm{CFR}<2.0$ were the HDL-C level $(\mathrm{OR}=0.934,95 \% \mathrm{CI}=0.891-0.980, \mathrm{P}=0.005)$ and hematocrit level $(\mathrm{OR}=1.531,95 \% \mathrm{CI}=1.036-2.264, \mathrm{P}=0.033)$. 
A

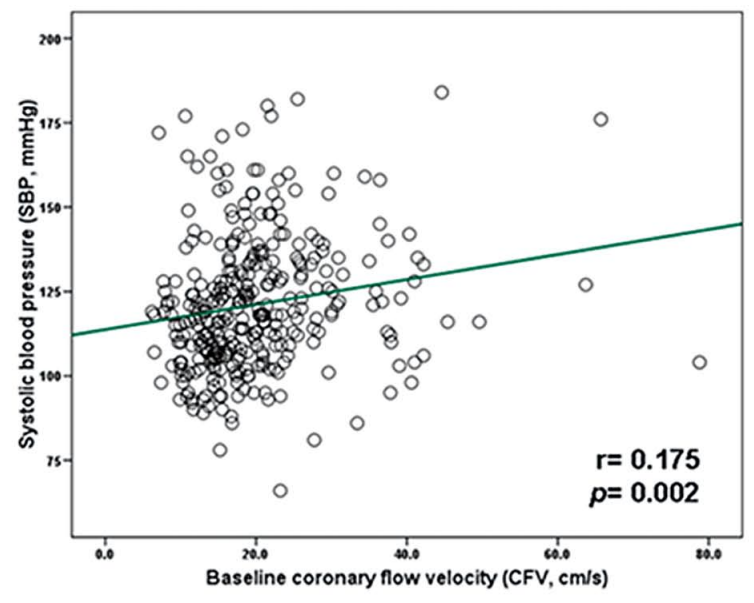

C

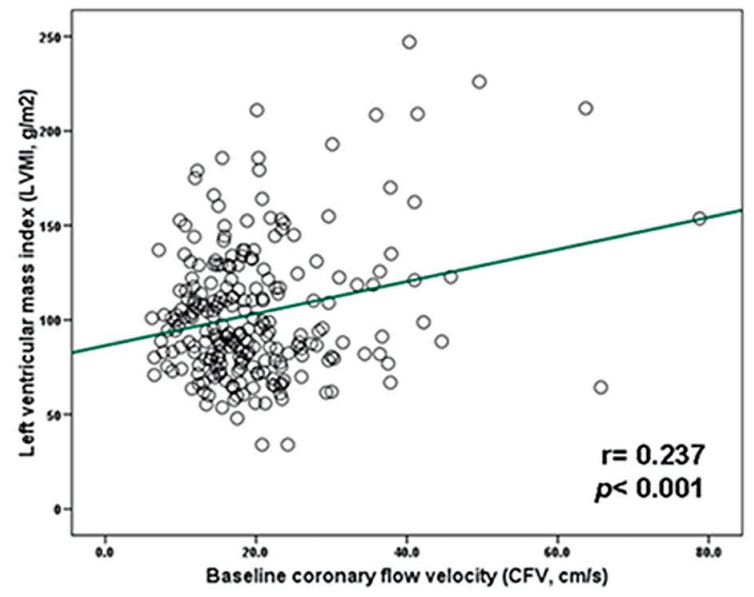

E

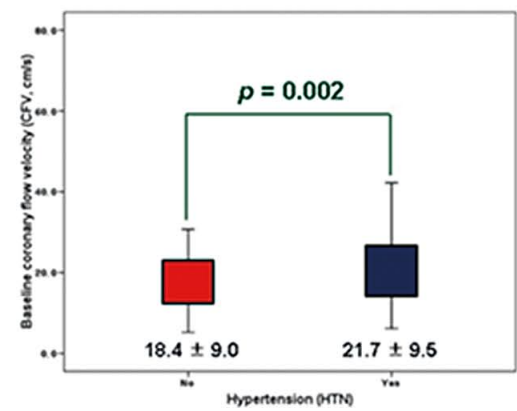

B

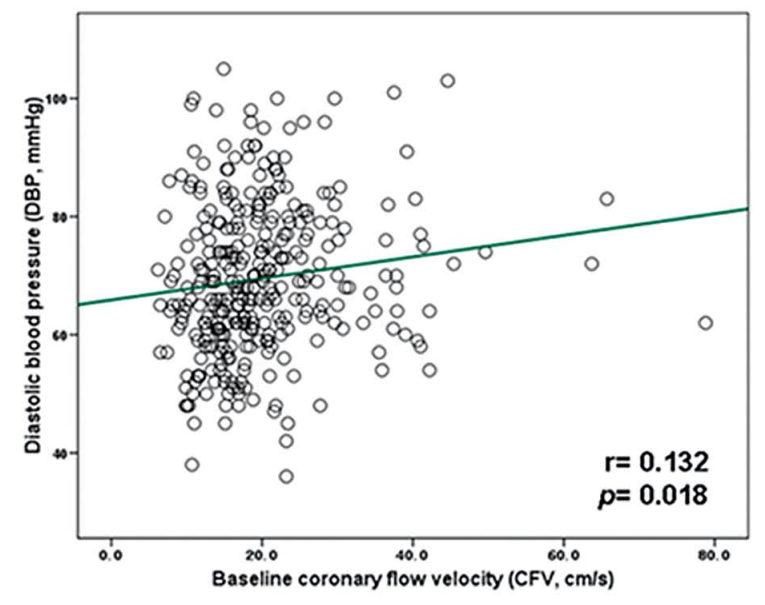

D

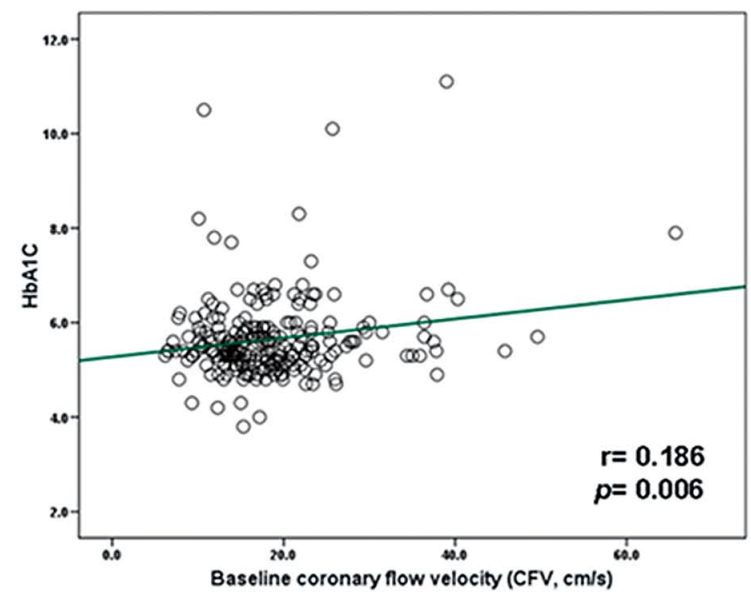

$\mathbf{F}$

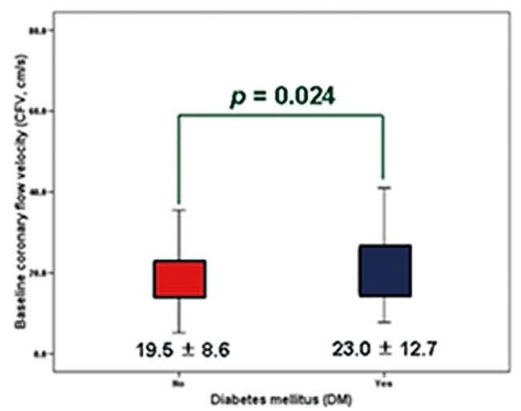

G

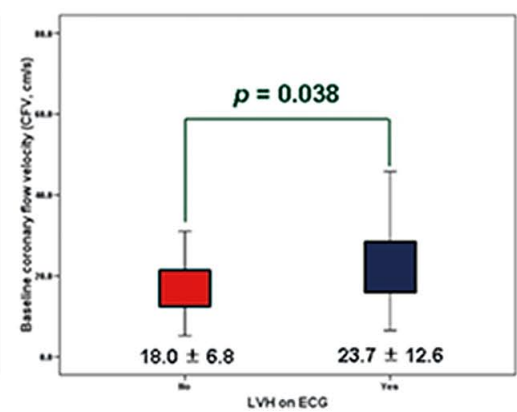

Figure 3. Parameters associated with baseline coronary flow velocity (CFV): (A) systolic blood pressure, (B) diastolic blood pressure, (C) left ventricular mass index and (D) hemoglobin A1c. Comparisons with baseline CFV level according to presence of disease: (E) hypertension, (F) diabetes mellitus and (G) left ventricular hypertrophy on electrocardiography.

\section{Discussion}

Microvascular angina has been classified as a form of angina pectoris and defined as the presence of angina-like chest pain, ST-segment depression during rapid atrial pacing, and normal coronary angiogram findings. Despite much research and interest, the pathophysiologic mechanism of this disease remains elusive ${ }^{4}$ and the continuous nature of the chest pain driving a continuous need for anti-anginal medications and in some cases re-hospitalizations are certainly troublesome to the patients and their physicians. ${ }^{3}$

CFR is defined as the ratio of baseline PDV to maximal hyperemic PDV. Several methods have been established for measuring CFR, which is important to the understanding of 
A

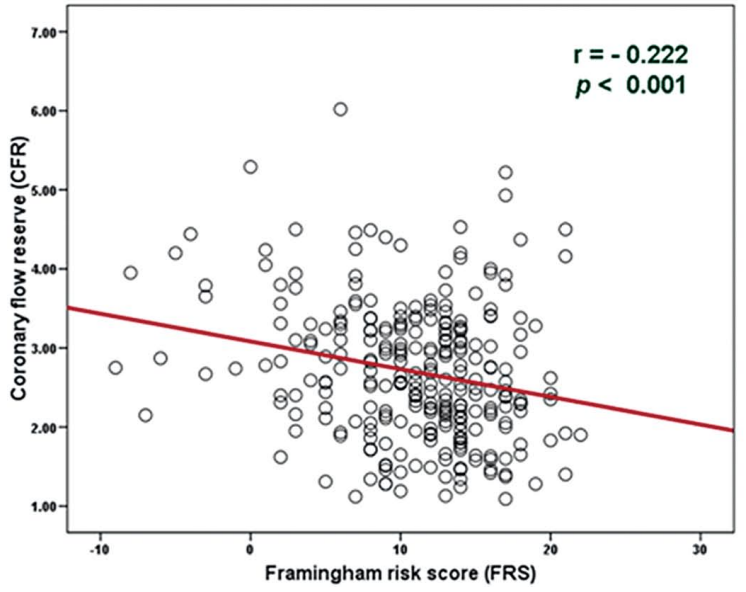

B

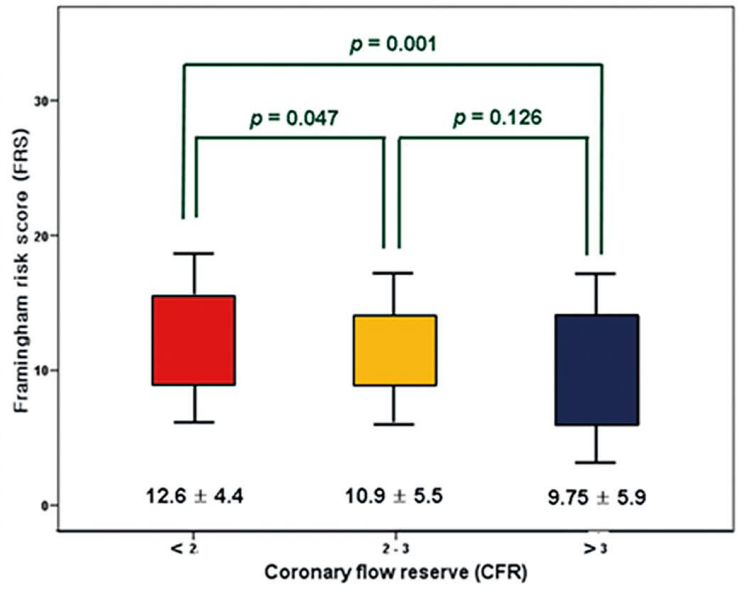

Figure 4. Relationship between (A) coronary flow reserve (CFR) and Framingham risk score, and (B) comparison among the 3 groups divided by CFRs of 2.0 and 3.0.

the pathophysiology of microvascular angina as well as for assessing stenosis of epicardial coronary arteries. Although the normal and ischemic ranges of CFR have not been determined as yet, CFR $>3.0$ has been reported as normal and CFR $<2.0$ has been suggested as an ischemic range. ${ }^{11,12}$

The Framingham risk scoring system published by the National Cholesterol Education Program serves as the gold standard in risk assessment for 10-year risk of CHD. ${ }^{22}$ To date, the relationships between CFR determined using TTE, and 10-year risk for myocardial infarction and coronary death have not been established. Furthermore, CFR may be decreased by the presence of coronary microvascular dysfunction and influenced by systemic hemodynamic conditions including blood pressure, heart rate, and myocardial contractility, as well as previous myocardial infarction, valvular heart disease and hypertrophic cardionyopathy. ${ }^{26,27}$

\section{Significance of Baseline CFV}

In the present study baseline CFV had an inverse correlation with CFR. Several studies reported that an upward shift of baseline CFV directly causes a reduction in CFR. ${ }^{13,28,29}$ These findings underscore the importance of baseline $\mathrm{CFV}$ in the prediction of CFR slowdown.

In the reports on an upward shift of baseline coronary flow in patients with hypertrophic cardiomyopathy, the pathologic mechanism is characterized by morphological changes including interstitial fibrosis and an increase in intramyocardial arteriolar wall thickness leading to functional alterations including diastolic dysfunction and a decrease in coronary reserve. ${ }^{26,27}$ Eventually, myocardial fibrosis increases the rate of onset of heart failure and arrhythmia. ${ }^{26}$ Youn et al reported that baseline CFV shifted upward in subjects with hypertensive hypertrophic cardiomyopathy could not lead to an increased amount of coronary blood flow and therefore predicted a decreased CFR. ${ }^{14-16}$

There are 2 lines of evidence that converge to support the observations in the present study. First, the higher the blood pressure and LVMI on echocardiography, the more the baseline CFV shifted upward. Second, the present results supported that LVH criteria on ECG were an independent predictor of baseline CFV in the highest $75 \%$ quartile (baseline CFV $\geq 23.2 \mathrm{~cm} / \mathrm{s}$ ).

\section{CFR Associated With Myocardial Ischemia}

In the present study, LVMI, HbAlc and LDL-C level were independent factors associated with CFR $<2.0$, defined as an ischemic range. In 1 previous study in subjects with normal coronary angiogram, the prevalence of hypertension was higher than that of normotension, ${ }^{14}$ while in another previous study, exercise-induced ST change was related to a decreased CFR in subjects with hypertensive hypertrophic cardiomyopathy. ${ }^{17,18}$

It is known that patients with diabetes mellitus have an increased risk for development of cardiac disease. There are some basic reasons why this is the case. Diabetes has direct effects on vascular and endothelial function, thereby increasing the potential for vasoconstriction and thrombosis. Furthermore, there is reasonable evidence that coronary vascular and endothelial function in patients with diabetes may be an early marker of atherosclerosis. ${ }^{19,30-33}$ A recent study showed marked coronary microvascular endothelial dysfunction in response to adenosine infusion, reflecting aberrant endothelium-independent vasodilatation, and to the cold pressor test, reflecting endothelium-dependent vasodilatation in young subjects with uncomplicated diabetes. ${ }^{34}$ This provides further support for a key role of hyperglycemia in the pathogenesis of microvascular endothelial dysfunction in diabetes. Also in the present study, it was documented that $\mathrm{HbA}_{1 \mathrm{c}}$ was an independent factor associated with $\mathrm{CFR}<2.0$, defined as an ischemic range.

It has been reported that CFR was significantly decreased in asymptomatic subjects with hypercholesterolemia and normal coronary angiogram, therefore suggesting the importance of reversibility of lipid profile with cholesterol-lowering strategies. ${ }^{35}$ In contrast, there is a report on a significant inverse relationship between CFR and levels of total cholesterol, ${ }^{36}$ which would suggest that the correction of the entire lipid profile is required as a treatment strategy. The present study found that the level of LDL-C was an independent factor associated with CFR $<2.0$. 


\section{Framingham Risk Scoring System and CFR}

The FRS is related to future CHD risk, and the present study has identified an inverse relationship with CFR. Age, HDL-C level and smoking status among the components of the Framingham risk scoring system were independent factors related to $\mathrm{CFR}<2.0$.

The Framingham risk scoring system, which was developed more than 50 years ago, does not provide a more accurate estimate of global CHD risk because it does not include other CHD risk parameters beyond the ones considered in the present study, namely age, total cholesterol, HDL-C level, systolic blood pressure, treatment for hypertension, and cigarette smoking.

Furthermore, we propose that research using other modalities, such as novel serum markers, electron beam computed tomography, magnetic resonance imaging, multidetector computed tomography, positron emission tomography, ankle-brachial blood pressure index testing and intima-media thickness is required.

\section{Study Limitations}

There were some limitations in the present study. Although CFR is defined as the capacity to increase oxygen supply in response to cardiac activity, which increases the oxygen demand of the myocardium, the definition of CFR $<2.0$ as an ischemic range has been established in patients with significant epicardial coronary artery stenosis. To clarify ischemic events in subjects with microvascular angina, however, further analysis of CFR is warranted.

Because the present study found coronary microvascular endothelial dysfunction in response to endothelium-independent vasodilatation including adenosine or dipyridamole infusion, we propose that a more comprehensive assessment of the coronary microvascular endothelial dysfunction requires separate investigation of both the endothelium-independent and -dependent vasomotor responses.

The present data indicated absence of cardiac death, which was indicated as a good prognosis for the 4-year follow-up period. Although CFR was related to some components of the Framingham risk scoring system-estimated 10-year risk for CHD, long-term follow up of at least 1 decade is required to clarify the clinical significance of CFR in subjects with microvascular angina.

\section{Conclusion}

CFR may be a comprehensive indicator of cardiovascular risk factors, including components of the Framingham risk scoring system, in subjects with chest pain and a normal coronary angiogram.

As was the case with the CASS Registry, ${ }^{1}$ the present study showed that the prognosis in subjects with chest pain and normal coronary angiogram might be excellent, which could be confirmed on long-term follow up via telephone interview in the future.

\section{Acknowledgment}

This study was supported by a grant of the Seoul R\&BD Program of the Republic of Korea (10526).

\section{References}

1. Kemp HG, Kronmal RA, Vliestra RE, Frey RL. Seven year survival of patients with normal or near normal coronary arteriograms: A CASS registry study. J Am Coll Cardiol 1986; 7: 479-483.

2. Wieglosz AT, Fletcher RH, McCants CB, McKinnis RA, Haney
TL, Willams RB. Unimproved chest pain in patients with minimal or no coronary disease: A behavioral phenomenon. Am Heart $J$ 1984; 108: $67-72$

3. Bemiller CR, Pepine CJ, Rogers AK. Long term observations in patients with angina and normal coronary arteriogram. Circulation 1973; 47: 36-43.

4. Kemp HG Jr. Left ventricular function in patients with the anginal syndrome and normal coronary arteriograms. Am J Cardiol 1973; 32: $375-376$.

5. Gould KL, Kirkeeide RL, Buchi M. Coronary flow reserve as a physiologic measure of stenosis severity. J Am Coll Cardiol 1990; 15: $459-474$.

6. Tanaka $S$, Noda $T$, Segawa $T$, Minagawa $T$, Watanabe $S$, Minatoguchi S. Relationship between functional exercise capacity and functional stenosis in patients with stable angina and intermediate coronary stenosis. Circ J 2009; 73: 2308-2314.

7. Takahashi T, Hiasa Y, Ohara Y, Miyazaki S, Ogura R, Suzuki N, et al. Relationship of admission neutrophil count to microvascular injury, left ventricular dilation, and long-term outcome in patients treated with primary angioplasty for acute myocardial infarction. Circ J 2008; 72: 867-872.

8. Hozumi T, Yoshida K, Akasaka T, Asami Y, Ogata Y, Takagi T, et al. Noninvasive assessment of coronary flow velocity and coronary flow reserve in the left anterior descending coronary artery by Doppler echocardiography: Comparison with invasive technique. J Am Coll Cardiol 1998; 32: 1251-1259.

9. Hozumi T, Yoshida K, Ogata Y, Akasaka T, Asami Y, Takagi T, et al. Noninvasive assessment of significant left anterior descending coronary artery stenosis by coronary flow velocity reserve with transthoracic color Doppler echocardiography. Circulation 1998; 97: $1557-1562$.

10. Youn HJ, Park CS, Cho EJ, Chung HO, Jeon HK, Lee JM, et al. Clinical significance of slow flow velocity in the distal left anterior descending coronary artery detected by transthoracic Doppler echocardiography. Korean Circ J 2002; 32: 299-308.

11. Youn HJ, Park CS, Cho EJ, Chung HO, Jeon HK, Chung WS, et al. Coronary artery flow velocity pattern predicting myocardial recovery after acute anterior myocardial infarction. Korean Circ J 2003; 33: $259-268$.

12. Youn HJ, Foster E. Demonstration of coronary artery flow using transthoracic Doppler echocardiography. J Am Soc Echocardiogr 2004; 17: $178-185$

13. Youn HJ. Significance of upward shift of baseline coronary flow velocity. Korean Circ J 2002; 32: 205-206.

14. Youn HJ, Ihm SH, Lee JM, Park CS, Cho EJ, Jung HO, et al. Relation between flow reserve capacity of penetrating intramyocardial coronary arteries and myocardial fibrosis in hypertension: Study using transthoracic Doppler echocardiography. J Am Soc Echocardiogr 2006; 19: 373-378.

15. Youn HJ, Lee JM, Park CS, Ihm SH, Cho EJ, Jung HO, et al. The impaired flow reserve capacity of penetrating intramyocardial coronary arteries in apical hypertrophic cardiomyopathy. J Am Soc Echocardiogr 2005; 18: $128-132$.

16. Youn HJ, Redberg RF, Schiller NB, Foster E. Demonstration of penetrating intramyocardial coronary arteries with high-frequency transthoracic echocardiography and Doppler in human subjects. J Am Soc Echocardiogr 1999; 12: 55-63.

17. Youn HJ, Park CS, Moon KW, Oh YS, Chung WS, Kim JH, et al. Relation between Duke treadmill score and coronary flow reserve using transesophageal Doppler echocardiography in patients with microvascular angina. Int J Cardiol 2005; 98: 403-408.

18. Youn HJ, Park CS, Cho EJ, Jung HO, Jeon HK, Lee JM, et al. Pattern of exercise-induced ST change is related to coronary flow reserve in patients with chest pain and normal coronary angiogram. Int J Cardiol 2005; 101: 299-304.

19. Park CS, Youn HJ, Kim JH, Cho EJ, Jung HO, Jeon HK, et al. Relation between peripheral vascular endothelial function and coronary flow reserve in patients with chest pain and normal coronary angiogram. Int J Cardiol 2006; 113: 118-120.

20. Youn HJ, Park CS, Cho EJ, Jung HO, Jeon HK, Lee JM, et al. Left bundle branch block disturbs left anterior descending coronary artery flow: Study using transthoracic Doppler echocardiography. J Am Soc Echocardiogr 2005; 18: 1093 - 1098.

21. Youn HJ, Ihm SH, Park CS, Oh YS, Chung WS, Kim JH, et al. Noninvasive assessment of coronary vasodilating capacity using freehand 3-dimensional echocardiography with rotational scanning. $J$ Am Soc Echocardiogr 2007; 20: 113-118.

22. National Cholesterol Education Program (NCEP) Expert Panel on Detection, Evaluation, and Treatment of High Blood Cholesterol in Adults (Adult Treatment Panel III). Third report of the National 
Cholesterol Education Program (NCEP) expert panel on detection, evaluation, and treatment of high blood cholesterol in adults (Adult Treatment Panel III), final report. Circulation 2002; 106: $3143-$ 3421 .

23. Sokolow M, Lyon TP. The ventricular complex in ventricular hypertrophy as obtained by unipolar precordial and limb leads. Am Heart J 1949; 37: $161-186$.

24. Gibbons RJ, Balady GJ, Bricker JT, Chaitman BR, Fletcher GF, Froelicher VF, et al. ACC/AHA 2002 guideline update for exercise testing: Summary article: A report of the American College of Cardiology/American Heart Association Task Force on Practice Guidelines (Committee to Update the 1997 Exercise Testing Guidelines). Circulation 2002; 106: $1883-1892$.

25. Lang RM, Bierig M, Devereux RB, Flachskampf FA, Foster E, Pellikka PA, et al. Recommendations for chamber quantification: A report from the American Society of Echocardiography's guidelines and standards committee and the chamber quantification writing group, developed in conjunction with the European Association of Echocardiography, a branch of the European Society of Cardiology. J Am Soc Echocardiogr 2005; 18: 1440-1463.

26. Rossi MA. Pathologic fibrosis and connective tissue matrix in left ventricular hypertrophy due to chronic arterial hypertension in humans. J Hypertens 1998; 16: 1031-1041.

27. Frohlich ED. Fibrosis and ischemia: The real risks in hypertensive heart disease. Am J Hypertension 2001; 14: 194-199.

28. Cannon RO 3rd, Schenke WH, Maron BJ, Tracy CM, Leon MB, Brush JE Jr, et al. Differences in coronary flow and myocardial metabolism at rest and during pacing between patients with obstructive and patients with nonobstructive hypertrophic cardiomyopathy.
J Am Coll Cardiol 1987; 10: 53-62.

29. Kozàkovà M, Palombo C, Pratali L, Pittella G, Galetta F, L'Abbate A. Mechanisms of coronary flow reserve impairment in human hypertension: An integrated approach by transthoracic and transesophageal echocardiography. Hypertension 1997; 29: 551-559.

30. Yokoyama I, Momomura S, Ohtake T, Yonekura K, Nishikawa J, Sasaki Y, et al. Reduced myocardial flow reserve in non-insulindependent diabetes mellitus. J Am Coll Cardiol 1997; 30: 1472 1477.

31. Pitkänen OP, Nuutila P, Raitakari OT, Rönnemaa T, Koskinen PJ, Iida $\mathrm{H}$, et al. Coronary flow reserve is reduced in young men with IDDM. Diabetes 1998; 47: 248-254.

32. Vanhoutte PM. Endothelial dysfunction: The first step toward coronary arteriosclerosis. Circ J 2009; 73: 595-601.

33. Maseri A, Beltrame JF, Shimokawa H. Role of coronary vasoconstriction in ischemic heart disease and search for novel therapeutic targets. Circ J 2009; 73: 394-403.

34. Di Carli MF, Janisse J, Grunberger G, Ager J. Role of chronic hyperglycemia in the pathogenesis of coronary microvascular dysfunction in diabetes. J Am Coll Cardiol 2003; 41: 1387-1393.

35. Gould KL, Martucci JP, Goldberg DI, Hess MJ, Edens RP, Latifi R, et al. Short-term cholesterol lowering decreases size and severity of perfusion abnormalities by positron emission tomography after dipyridamole in patients with coronary artery disease. Circulation 1994; 89: $1530-1538$

36. Kaufmann PA, Gnecchi-Ruscone T, Shafers KP, Luscher TF, Camici PG. Low density lipoprotein cholesterol and coronary microvascular dysfunction in hypercholesterolemia. J Am Coll Cardiol 2000; 36: $103-109$. 